\title{
Europe's beating cancer plan \& citizens' engagement - The case history of the civic monitoring of onco-hematological Day Hospitals across Italy
}

\author{
Mariano Votta ${ }^{1 *}$, Valeria Fava ${ }^{2}$ and Maira Cardillo ${ }^{3}$ \\ ${ }^{1}$ Director of Active Citizenship Network and Responsible EU Affairs, Cittadinanzattiva, Italy \\ ${ }^{2}$ Civic Observatory on Federalism in Healthcare, Cittadinanzattiva, Italy \\ ${ }^{3}$ Community \& Fellowship Assistant, Active Citizenship Network, EU Branch of Cittadinanzattiva, Italy
}

Every year, 3.5 million people in the EU are diagnosed with cancer, and 1.3 million people die from cancer each year. In fact, $40 \%$ of us are likely to face this disease at some stage of our life. The EU has been actively working to reduce the incidence of cancer for decades and, in the last few months, the President of the European Commission has invited all interested individuals and organizations to share their views and experiences in order to create a Europe's Beating Cancer Plan and put European citizens at the center. To be honest, too many times we have heard that the patient must be put at the center: will this be the right time? Much will depend on the ability to give concrete answers to what citizens and patients ask, that is: more prevention \& information; consideration of the patients' psychological and socioeconomic conditions, and support to their families; uniformity of care and fair access to health services \& innovative technologies; GPs training \& integration/better communication with the specialist; fight against the lack of continuity of care in the treatment path, waiting lists \& bureaucracy; patient-centered care pathways/personalization of care paths; greater listening by HCPs \& patients' involvement in the treatment plan; lower costs for the citizens \& greater patient safety; job protection \& integration of public social policies (care benefit/civil disability; school integration; overcome the isolation of the elderly, etc.).

Encouraging, however, the fact that the first question of the Public consultation on the Commission's Europe's Beating Cancer Plan (closed on 21 May 2020) referred to what citizens can do to help beat cancer.

In line with our mission (which encourages the active participation of citizens in the policy-making process, recognizing the primary role of citizens and civic organizations in the care of common goods, starting from health) and with our multiannual commitment on the topic, Cittadinanzattiva, also thanks to its European network Active Citizenship Network, has actively responded to the open consultation on the topic of Europe's Beating Cancer Plan.

On the other hand, in Italy, the oncology area appears to be among those in which Cittadinanzattiva collects each year the highest number of reports and requests of support. The majority of the reports concerned access to therapies and in particular: dysfunctional health services with high disparities in quality from region to region, the difficulty in accessing drug therapies in a timely manner, discontinuity of care between hospital and territory, inter-regional mobility, the lack of humanization of care.

The hope is that the new Cancer Plan could respond to the main gaps found by citizens, reducing health inequities and disparities that are unacceptable between States, and also between Regions within the same Country: In Italy, for instance, the concrete access of innovative oncological medicines varies from 0-15 days to 61 days. EU should ensure a more rapid access to innovative medicines, strengthen the knowledge of patient organizations and ensure timely access to therapies for severe diseases with unmet medical needs.

Obviously, expectations are high for the impact of the new Europe's Beating Cancer Plan: we are convinced that it is a great opportunity to tackle some concrete ambitious public health goals: for instance, Hepatitis B-attributable liver cancer and HPV-attributable cervical cancer are two cancers that can be eliminated in Europe. Yet this will only be possible if appropriate frameworks are put in place and implemented at national level and if dedicated prevention and immunization funds are unlocked by EU member states. In line with our commitment on vaccination and our role in the ECDC Technical Advisory Group dealing with increasing vaccine coverage, we'll work in this direction.

At the same time, as members of the Global Lung Cancer Coalition, we hope in a more effective fight against smoking. Furthermore, as past members of the technical committee of the Italian Ministry of Health on Pain Therapy and Palliative Care, and Member of the Societal Impact of Pain at the EU level, Cittadinanzattiva/Active Citizenship Network will be glad to support Europe's Beating Cancer Plan by collecting good practices and promoting pain cancer-related awareness initiatives and supporting the network of managers active on the topic.

Crucial is also the opportunity to avoid any silos approach in front of other existing initiatives promoted by the EU Institutions: what about the connection with the European Pillar of Social Rights (relevant for the cancer survivorship) as well as with the ERNs dealing with rare cancer? For this second aspect, we strongly suggest, for instance, to encourage a multi-stakeholder forum, opened to all the actors already involved in the Cross-border Healthcare context and in the implementation of its Directive, including the promoters of Digital Health solutions and civic \& patients' representatives.

${ }^{*}$ Correspondence to: Mariano Votta, Director of Active Citizenship Network and Responsible EU Affairs, Cittadinanzattiva, Italy, E-mail: m.votta@ activecitizenship.net

Received: May 30, 2020; Accepted: June 22, 2020; Published: June 24, 2020 
Specifically, many are the indications advanced by CittadinanzattivaActive Citizenship Network through the first mentioned Cancer Plan consultation: among the others, the need to strengthen the multidisciplinary approach as well as the personalized medicine; to officially recognize and harmonize the role of the caregivers; to provide paths that prepare and support the patient and family members against the side effects of treatments (such as infertility, sexual dysfunctions, anxiety, etc.); to overcome the logic of price to better analyze direct and indirect costs of the diseases and so to affirm more wide-ranging assessments (VBHC model). Essential is also the need to strengthen within each Member States and across Europe oncological networks to help guarantee early management, efficient therapeutic diagnostic courses, continuity and follow-up of care. Oncological networks must be in synergy with each other and must focus on investing in innovative models and therapies that contribute to improving the lives of patients and making the healthcare system sustainable and available at all times and in the most efficient manners. In fact, the main issue described by patients probably focuses on the endless waits for therapy, as the experience described below shows. As the COVID-19 pandemic testifies, it is important to relocate oncological treatments by strengthening the structures that operate outside hospitals and, last but not least, there is also the need to better recognize the role of health workers, also for their key role on patient orientation both in accessing services and in choosing care opportunities, and in informing and promoting the theme of prevention (correct lifestyles, vaccines and screenings).

To come back to the initial question of the Public consultation on the Cancer Plan, referring to the role citizens can play to help beat cancer, we have underlined the importance of producing civic information, collecting data, making proposals and opening a dialogue with public \& private bodies and relevant stakeholders in order to improve the quality standards of health services. This is possible solely if civic participation in healthcare is guaranteed and if the citizen is recognized as an active subject in the fight against cancer. In Italy, for many years by now, Cittadinanzattiva has involved citizens in carrying out civic monitoring of oncological structures. This was done to detect, from the citizen's perspective, the functioning and the problems to be subjected to protective action and to verify its solution over time. How to give effectiveness to all this? The experience described below, translating a statement of principle "citizens at the center" into a participatory practice, represents a concrete way to give weight to the civic point of view in the oncology field.

\section{Civic monitoring of onco-hematological day hospitals}

The civic monitoring of onco-hematological Day Hospitals conducted by Cittadinanzattiva-Tribunal for Patients' Rights, in collaboration with AIL, the Italian Association struggling against blood diseases, and carried out thanks to the unconditioned support of Roche, has presented a detailed picture of the current situation in Italy. The monitoring was carried out along 2019 in 46 onco-hematological Day Hospitals (DH) and then officially presented to the Institutions and relevant stakeholders in Rome. From the civic monitoring, it emerged that $85 \%$ of the patients positively judge the professionalism and humanity of health care workers and the overall quality of the provided services. Positive opinion also for the times related to the start of chemotherapy (delivered to all patients within 30 days), but patients are unsatisfied with the waiting times that go up to 8 hours, with the inefficient organization of services and the poor computerization: investing in the organization and in computerization and fully benefit from their potential is necessary in the 21 st century!

\section{Attention to patients' needs: partially rejected}

Going deeper into the report, the data gathered show that over $36 \%$ of Day Hospitals do not have a service orientation activity, where most of the information is communicated verbally or posted on the bulletin board, while only in $46 \%$ of the cases the printing of specific brochures/ leaflets is provided. The worse situation arises on the front of the aid for administrative practices: although it is a form of support widely foreseen in Day Hospitals, work still must be done in order to really make it a guaranteed practice in all facilities, since 4 people out of 10 claim that they have not received it. In particular, a difficulty in facilitating practices for having prostheses and aids emerges (72\%). Furthermore, although $80 \%$ of Day Hospitals claim to have activated a phone service to manage any critical issues felt by patients in the management of the disease or therapy (side effects, doubts about medicines to take at home, etc.), the latter criticize the quality and timeliness: barely enough for $22 \%$ of the patients and poor for more than the $7 \%$. The opening hours of the service is reduced, often it is not open during the afternoon hours and it is not constantly monitored because it is managed by a small number of workers already overloaded of other work.

$15 \%$ of patients declare that "white" prescriptions have been issued by the facility's specialists, without any direct reservation of the visits and control services as instead requires the taking care of the patient. This practice weighs on the patient since he must necessarily refer to the family doctor for the prescription and later on refer to the call center of the Day Hospitals to take an appointment. It often happens that, within the prescription, doctors do not specify the priority class, and this further complicates the actual delivery of the service within the time needed by the patient.

\section{The endless waits for therapy}

The time required to perform the drug therapy goes from a minimum of 1 hour up to 8 hours. The greater frequency of hours of stay concerns a waiting time of 3-4 hours (43\%) and from 5 to 6 hours $(28 \%)$. More than $8 \%$ report staying up to 8 hours in total.

Almost $80 \%$ of the facilities use software, however it is mainly used to manage the appointment agenda. Far lower percentages are identified for organizing appointments based on the type of treatment $(71,4 \%)$ and even less based on the duration criterion (57\%).

Still contained is the percentage of facilities able to trace down the path of the single patient during the various phases of the day and also record the average execution time, in order to have precise data on the time of the process the patient has to go through and verify any critical issue and reducible times. Even fewer are the facilities which use the data gathered to initiate path improvement actions.

Regarding the organization of appointments, more than 13\% of the facilities declare to call all patients at the same time without distinguishing between the type of therapy, long or short, they will have to undergo. Most of Day Hospitals provide for the separation of the paths for control exams from those for the administration of the therapy, but even in this case, several facilities (over 13\%) make no distinction, gathering all patients regardless of the purpose for which they are called. Moreover, more than $90 \%$ of $\mathrm{DH}$ affirm that there are delays in making the medicine available to the patient, mainly due to organizational dysfunctions.

Over $26 \%$ of patients retain that in the phase before the administration of the therapy there is a lot of downtime that could be improved and reduced. In $25 \%$ of the cases it is the waiting time for the blood test that is considered excessive and a downtime. The waiting 
time for the visit also results critical (15\%); this phase is preceded by the reporting of blood tests, a phase that requires, together with the preparation of the medicine, the longest time.

Above all, it is the waiting for the therapy, that is the time that goes from the visit to the entrance to the administration room that is considered to be the one in which greater downtimes can be seen (50\%). Of this time, it is in particular the waiting for the chair to become free (35\%) that is perceived as a downtime. Patients often notice free chairs without any patient going over; as a matter of fact, more than $80 \%$ do not even use software to organize the administration shifts.
To conclude, it emerges from the civic monitoring that, in general, it is the organization of services that arises as being focused on one's own needs and not on those of the patients. Useless and easily reducible waiting times, little respect for the quality of patients' life, referral from a specialist to another, and little information are all different sides of the same issue, that is the distance that still exists for the patient to feel at the center. Citizens' organizations can represent the added value in the solution of the difficulties that have emerged. A message that we hope can be conveyed even at the European level during the drafting and subsequent implementation of the new cancer plan.

Copyright: @2020 Votta M. This is an open-access article distributed under the terms of the Creative Commons Attribution License, which permits unrestricted use, distribution, and reproduction in any medium, provided the original author and source are credited. 